\title{
Treatment of large airway obstruction in lung cancer using expandable metal stents inserted under direct vision via the fibreoptic bronchoscope
}

\author{
G E Wilson, M J Walshaw, C R K Hind
}

\begin{abstract}
Background - Self-expanding metal stents have been used successfully to overcome large airway obstruction due to malignant pulmonary disease. The technique has been modified to place stents under direct vision using the fibreoptic bronchoscope. The effect of this procedure on lung function and patient well being was in-
\end{abstract} vestigated in a large series of patients.

Methods - Fifty six patients with malignant tracheobronchial tumours were treated for symptoms of life threatening airways obstruction or collapse of a lung by the insertion of an expandable metal stent(s) under local anaesthetic using a fibreoptic bronchoscope. All had inoperable cancer and 33 had relapsed after or failed to respond to radiotherapy, chemotherapy, or surgery. Forty seven had primary bronchial carcinomas and nine had metastases from other tumour sites. All but two patients had the stents inserted at one sitting. Measurements were performed in most of the patients before and after stenting and included objective measures (pulmonary function tests, arterial blood gas tensions) and non-objective measures (patient well being, performance status). Results - Overall, $77 \%$ of patients showed symptomatic improvement. In those patients in whom measurements were performed two thirds showed improvement in forced expiratory volume in one second $\left(F E V_{1}\right)$, forced vital capacity (FVC), peak expiratory flow rate (PEFR) and arterial oxygen tension $\left(\mathrm{PaO}_{2}\right)$. Medical Research Council dyspnoea score (MRC), Karnofsky, and visual analogue scores (for both breathing and well being) improved in $81 \%$ of patients. There were no perioperative deaths. Fifty one patients have died since the procedure with a mean survival of 77 days (range 1-477), and five patients are still alive after a mean of 207 days (range 135-274).

Conclusions - In suitable patients with either extraluminal or intraluminal tumour, or both, the insertion of expandable metal stents using a fibreoptic bronchoscope and local anaesthetic is a valuable addition to other palliative therapies in the treatment of lung cancer.

(Thorax 1996;51:248-252)

Keywords: stents, tracheobronchial tumours, fibreoptic bronchoscopy.
Large airway obstruction due to primary lung cancer or spread from non-bronchial malignancies can produce life threatening and distressing breathlessness, either as an acute presenting symptom of the underlying disease or when recurrence occurs after other treatment. Expandable metal stents have been used successfully to relieve airway obstruction in such patients. ${ }^{12}$ In these case reports the procedure was carried out under general anaesthesia using a rigid bronchoscope and fluoroscopic imaging. This approach limits its use to centres where rigid bronchoscopy is available, and to those patients who are well enough to withstand general anaesthesia.

To overcome these difficulties we have modified the procedure by inserting these expandable stents under direct vision using a fibreoptic bronchoscope and local anaesthesia only. We report here our experience of this novel approach in 56 patients, and our assessment of the effectiveness of this therapy in the palliation of inoperable lung cancer.

\section{Methods}

A total of 56 patients with respiratory distress due to malignant obstruction of the trachea and/or a main bronchus have now undergone this procedure ( 33 men) of mean age 64 years (range 30-82). Forty seven had primary bronchial carcinomas and nine had endobronchial metastases from a cancer elsewhere in the body (table 1). Of the 56 patients 33 had suffered relapse after conventional treatment with radio-

Table 1 Histological type of primary bronchial carcinomas $(n=47)$, primary site of tracheobronchial metastases $(n=9)$, and previous treatment in patients with malignant tracheobronchial disease $(n=33)$

\section{No of patients}

\begin{tabular}{lr}
\hline Primary tumour type $(\mathrm{n}=47)$ & 25 \\
Squamous cell & 3 \\
Non-small cell & 6 \\
Small cell & 4 \\
Adenocarcinoma & 1 \\
Adenosquamous & 9 \\
Presumed carcinoma & 3 \\
Secondary tumour $(\mathrm{n}=9)$ & 2 \\
Oesophagus & 2 \\
Breast & 1 \\
Thyroid & 1 \\
Melanoma & 17 \\
Colon & 5 \\
Previous treatment $(\mathrm{n}=33)$ & 4 \\
Radiotherapy & 3 \\
Pneumonectomy & 2 \\
Chemotherapy & 1 \\
Oesophagogastrectomy & 1 \\
Mastectomy & \\
Wedge resection & \\
Sigmoid colectomy &
\end{tabular}

Centre, Liverpool

L14 3PE, UK

G E Wilson 
Table 2 Site of malignant obstruction in the 56 patients

\begin{tabular}{ll}
\hline Site of obstruction & No of patients \\
\hline Trachea & 20 \\
Right bronchial tree & 10 \\
Left bronchial tree & 12 \\
Both main bronchi & 3 \\
Trachea and left main bronchus & 4 \\
Trachea and right main bronchus & 3 \\
Trachea and both main bronchi & 6 \\
\hline
\end{tabular}

therapy, chemotherapy or surgery (table 1), and the remainder (23 patients) were undergoing stent insertion as a primary procedure. The sites of obstruction within the tracheobronchial tree are shown in table 2 .

The 56 patients were treated over a three year period. The stents used (see below) are available in a range of widths and lengths. In this study we used the following sizes: $20 \mathrm{~mm}$ (width) $\times 25 \mathrm{~mm}$ (length), $20 \mathrm{~mm} \times 50 \mathrm{~mm}$, $30 \mathrm{~mm} \times 25 \mathrm{~mm}$, and $30 \mathrm{~mm} \times 50 \mathrm{~mm}$. In general the $20 \mathrm{~mm}$ width stents were used for obstruction in the main bronchi and $30 \mathrm{~mm}$ stents for obstruction in the trachea.

Response to treatment was firstly assessed by the patient's account of their symptoms (using a visual analogue score for breathing and another for well being). The Medical Research Council (MRC) score of breathlessness ${ }^{3}$ and the Karnofsky index ${ }^{4}$ were then completed by a doctor. Secondly, the results of lung function studies before and after stenting were recorded including forced expiratory volume in one second $\left(\mathrm{FEV}_{1}\right)$, forced vital capacity (FVC), and peak expiratory flow rate (PEFR) measured on a Jaeger Masterlab system. Arterial blood gas tensions were also measured before and after stenting. However, not all of the prestenting assessments could be completed in some patients because of extreme breathlessness or where the stenting was carried out as an emergency when the facilities were not available. Where measurements were able to be carried out the prestenting values were obtained within the preceding 24 hours (or less), and the poststenting values were obtained up to 72 hours after stenting. The visual analogue scores of breathlessness and well being consist of a $100 \mathrm{~mm}$ analogue scale. ${ }^{5}$ The ends of the scale are marked "very, very breathless" and "not at all breathless" and "very, very ill" and "very, very well", respectively. The patients placed a mark on the $100 \mathrm{~mm}$ scale to indicate how they felt at the time of each assessment. A score of $0 \mathrm{~mm}$ was the worst possible and $100 \mathrm{~mm}$ the best.

The results were analysed using the Student's $t$ test for paired samples on Minitab statistical software. A p value of 0.05 was considered significant.

Each patient received our standard regimen of intravenous sedation with droperidol and fentanyl (neuraleptanalgesia), a transtracheal injection of $5 \%$ cocaine, and spraying of the pharynx with topical xylocaine. All patients received supplementary oxygen via nasal cannulae $(6 \mathrm{l} / \mathrm{min})$, and oxygen saturation was monitored using an oximeter attached via a finger probe.

\section{TECHNIQUE}

The fibreoptic bronchoscope was passed through the mouth via a gum shield and positioned above the obstructing lesion in the trachea or main bronchus. A flexible guide wire (Teflon coated, $260 \mathrm{~cm} \times 0.035^{\prime \prime}$; Cordis Corporation, Miami, Florida, USA) was then inserted through the biopsy channel of the bronchoscope and pushed beyond the malignant narrowing. The bronchoscope was then removed whilst threading the wire through the
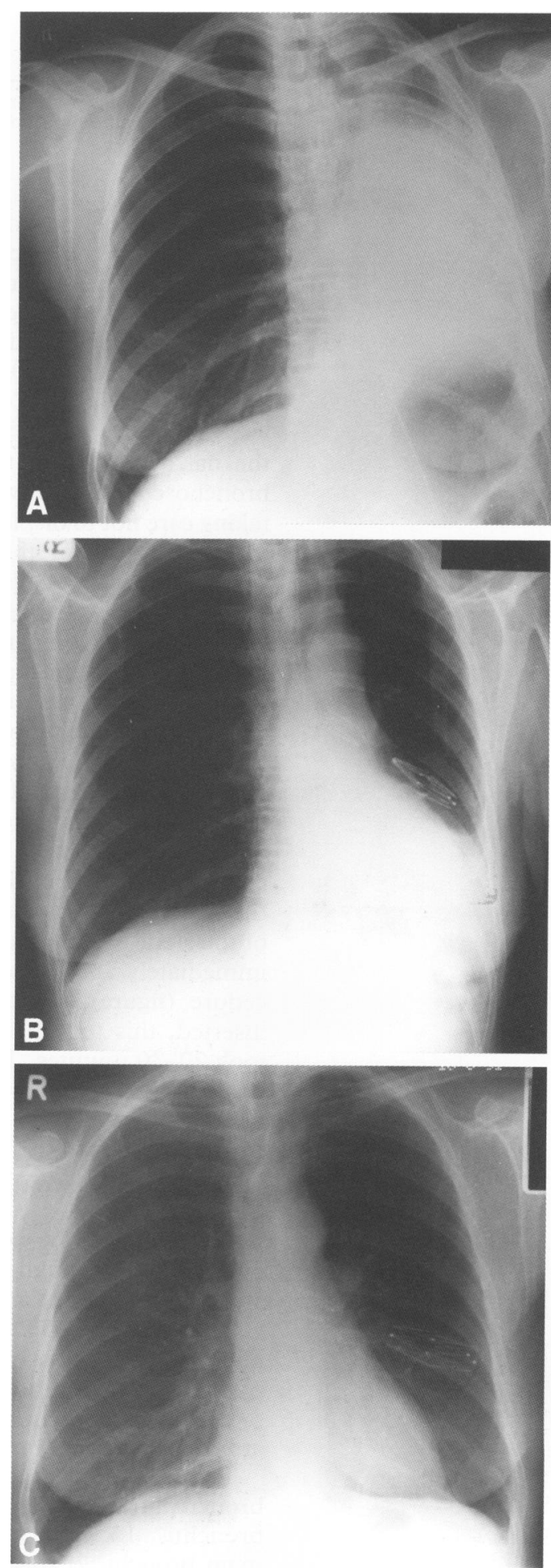

Chest radiographs taken $(A)$ before stenting showing the collapse of the left lung secondary to oesophageal carcinoma, (B) immediately after insertion of two $20 \mathrm{~mm} \times 50 \mathrm{~mm}$ and one $20 \mathrm{~mm} \times 25 \mathrm{~mm}$ stents, and $20 \mathrm{~mm} \times 50 \mathrm{~mm}$ and one $20 \mathrm{~mm} \times 25 \mathrm{~mm}$ stents, and
(C) 24 hours after stenting showing complete re-expansion of the left lung. 
Table 3 Comparison of mean (SD) values for spirometric parameters, PEFR, and arterial blood gases before and after stenting in all 33 patients, in those with tumours involving the trachea only $(n=16)$ and the main bronchi $(n=17)$

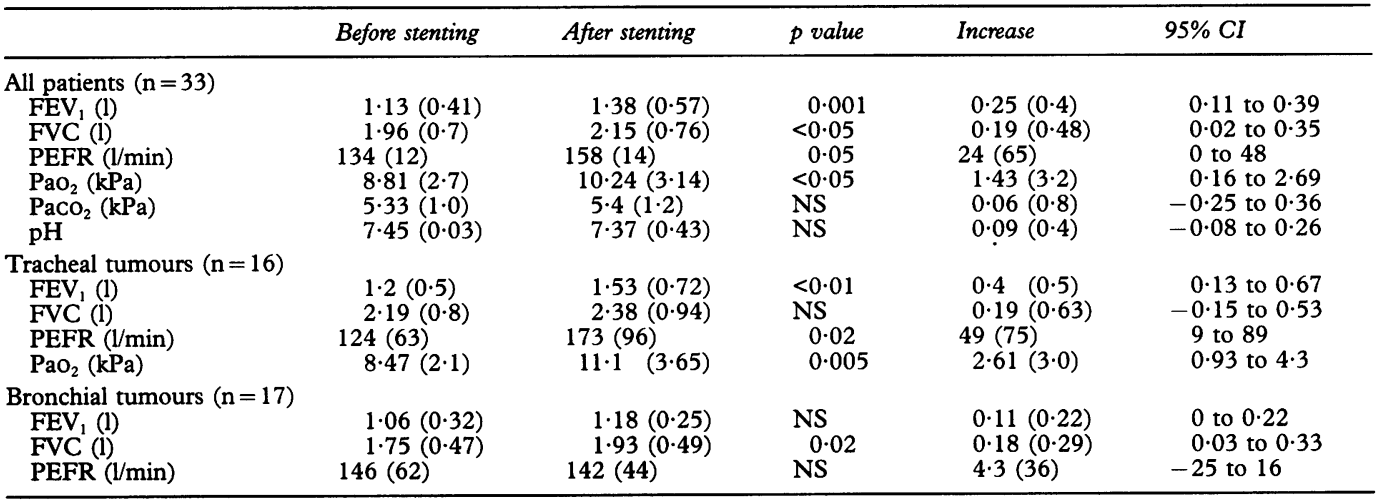

$\mathrm{FEV}_{1}=$ forced expiratory volume in one second; $\mathrm{FVC}=$ forced vital capacity; PEFR = peak expiratory flow rate; $\mathrm{PaO}_{2}, \mathrm{PaCO}_{2}=$ arterial oxygen and carbon dioxide tensions; $\mathrm{NS}=$ not significant.

suction channel to ensure the wire was left in position in the tracheobronchial tree. The bronchoscope was then reinserted through the mouth and positioned just above the vocal cords. The stent loading catheter (Gianturco $\mathrm{Z}$ stent $11 \cdot 0$ French, $90 \mathrm{~cm}$ radio opaque Teflon introducer; William Cook Europe, Denmark) was threaded over the wire and placed beyond the narrowing under the direct vision of the bronchoscopist. The wire was then removed, taking care not to displace the loading catheter. The inner part of the loading catheter was withdrawn and a collapsed stent (Gianturco self-expandable stainless steel $\mathrm{Z}$ stent; William Cook Europe, Denmark) was inserted into the proximal end of the loading catheter. This was then pushed to the distal end of the loading catheter using the supplied trocar. Under direct vision through the fibreoptic bronchoscope the stent was pushed out of the loading catheter and expanded as it was released. Initial immediate dilatation is followed by a further gradual increase in diameter of the narrowed airway over the next 24 hours. The position and opening of the stent was checked by a chest radiograph immediately and 24 hours following the procedure (figure). Where multiple stents were inserted, this took place at one sitting which took 20-30 minutes. The degree of bronchial/ tracheal obstruction was assessed visually by bronchoscopy.

\section{Results}

In most patients the stenting was carried out at one session, although two patients had further stenting carried out at a separate sitting.

Thirty patients (53\%) had $>90 \%$ obstruction of a main bronchus and the remaining 26 had partial obstruction (over $50 \%$ ) of their trachea or of a main bronchus (or both main bronchi) at bronchoscopic examination.

The stents were placed in the tracheobronchial tree as follows: trachea, 19; left main bronchus, 13; right main bronchus, 10; both main bronchi, 7; trachea and left main bronchus, 6; trachea and right main bronchus, 2; and trachea and both main bronchi, 1. The stents can be overlapped and placed in continuity with each other if the length of tumour is extensive. In this study a total of 117 stents were inserted (mean two stents per patient, range 1-4). As each introducer and guide wire currently cost $£ 85$, and each stent currently costs $£ 250$, the average cost per patient in our study was $£ 585$ (range $£ 335-1085$ ).

\section{CHEST RADIOGRAPHS}

Of the 13 patients with radiological evidence of complete lung collapse, four showed complete re-expansion after stenting (figure) and in the remainder there was some, albeit incomplete, expansion.

\section{LUNG FUNCTION STUDIES}

Of all the patients who underwent stenting, complete physiological data are available for 33. For all patients, irrespective of the site of the obstruction or whether stenting was a primary or secondary procedure, the results are shown in table 3. There were significant improvements in the $\mathrm{FEV}_{1}(\mathrm{p}=0.001)$, FVC $(p<0.05), \quad$ PEFR $\quad(p=0.05)$, and $\mathrm{PaO}_{2}$ $(\mathrm{p}<0.05)$. The changes in $\mathrm{PaCO}_{2}$ and $\mathrm{pH}$ did not reach a level of significance.

The effect of the tumour site was studied by dividing the patients into those with tumours involving the trachea $(n=32)$ and those with involvement of the main bronchi alone $(n=$ $24)$. In those with tracheal tumours $(n=16$ with complete data) the improvement in $\mathrm{FEV}_{1}$ $(p<0.01)$ was greater than in PEFR $(p=0.02)$; there was no significant change in the FVC. The $\mathrm{PaO}_{2}$ (air) increased by a mean of $2.61 \mathrm{kPa}$ $(p=0.005)$. In contrast, in patients with tumours involving the main bronchi alone $(n=$ 17) the FVC increased significantly $(p=0.02)$, but there was no significant change in the PEFR, $\mathrm{FEV}_{1}$ or $\mathrm{PaO}_{2}$.

We also compared the lung function in those patients who underwent stenting as a primary procedure for their underlying cancer with the group of patients in whom previous therapy had been carried out at some time in the past (table 4). The patients undergoing stenting as a primary procedure in whom complete physiological data were available $(n=13)$ showed a significant increase in $\mathrm{FEV}_{1}(\mathrm{p}<0.01)$ and FVC $(\mathrm{p}<0.01)$. In those patients in whom stenting was carried out as a secondary pro- 
Table 4 Comparison of mean values for spirometric parameters and PEFR in patients undergoing stenting as a primary procedure $(n=13)$ and as a secondary procedure $(n=20)$

\begin{tabular}{lcclcc}
\hline & Before stenting & After stenting & $p$ value & Increase & $95 \% C I$ \\
\hline Primary procedure: & & & & \\
FEV (1) & $1.02(0.42)$ & $1.4(0.64)$ & $<0.01$ & $0.38(0.43)$ & 0.12 to 0.64 \\
FVC (1) & $2.09(0.89)$ & $2.35(0.92)$ & $<0.01$ & $0.26(0.3)$ & 0.08 to 0.44 \\
PEFR (1/min) & $97(47)$ & $134(77)$ & NS & $37(66)$ & -4.6 to 79 \\
Secondary procedure: & & & & \\
FEV $(1)$ & $1.2(0.4)$ & $1.37(0.53)$ & NS & $0.17(0.38)$ & -0.01 to 0.34 \\
FVC (1) & $1.88(0.55)$ & $2.02(0.63)$ & NS & $0.14(0.57)$ & -0.13 to 0.4 \\
PEFR (1/min) & $159(60)$ & $175(74)$ & NS & $15(65)$ & -17 to 48 \\
\hline
\end{tabular}

$\mathrm{FEV}_{1}=$ forced expiratory volume in one second $\mathrm{FVC}=$ forced vital capacity; $\mathrm{PEFR}=$ peak expiratory flow rate.

Table 5 Comparison of mean values for MRC, Karnofsky, and visual analogue scores before and after stenting in 11 patients

\begin{tabular}{lccccc}
\hline & Before stenting & After stenting & $p$ value & Increase & $95 \%$ CI \\
\hline MRC & $5(0)$ & $4(1)$ & $0 \cdot 02$ & $0 \cdot 8(1)$ & $0 \cdot 16$ to $1 \cdot 5$ \\
Karnofsky & $29 \cdot 1(11 \cdot 4)$ & $51 \cdot 8(21 \cdot 4)$ & $0 \cdot 002$ & $22 \cdot 7(18)$ & $10 \cdot 7$ to $34 \cdot 8$ \\
VAS (B) & $40(23)$ & $63(22)$ & $<0 \cdot 05$ & $23 \cdot 2(30 \cdot 7)$ & $2 \cdot 56$ to $43 \cdot 8$ \\
VAS (W) & $51(23)$ & $65(25)$ & $<0 \cdot 05$ & 14 (18) & $2 \cdot 18$ to 26 \\
\hline
\end{tabular}

VAS $(B)=$ visual analogue score (breathing); VAS $(\mathrm{W})=$ visual analogue score (walking).

cedure $(n=20)$ none of the mean measured physiological parameters changed significantly.

The proportion of patients who achieved a change of 0.21 (or greater) in the $\mathrm{FEV}_{1}$ and FVC in the primary and secondary groups was also assessed. In the primary group this level of improvement was seen in $24 \%$ for FVC and $21 \%$ for $\mathrm{FEV}_{1}$. In the secondary group it was

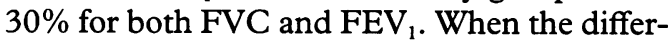
ence in the proportions was tested by the $\chi^{2}$ test it was found not to be significant.

\section{PATIENT ORIENTATED MEASURES}

Of the 56 patients who underwent stenting 11 had complete data on patient orientated measures. The MRC $(p=0 \cdot 02)$, Karnofsky $(p=0.002)$, and visual analogue scores for walking $(p<0.05)$ and breathing $(p<0.05)$ all changed significantly from the levels before stenting (table 5).

\section{COMPLICATIONS}

Four patients died within 24 hours of undergoing stenting; two had undergone a pneumonectomy in the past (one of whom developed a $30 \%$ contralateral pneumothorax treated by insertion of an intercostal drain), a third had a complete collapse of one lung, and the fourth had poor lung function before the procedure with an $\mathrm{FEV}_{1}$ of $25 \%$ predicted. This patient had six perioperative respiratory arrests from which she had been successfully resuscitated. She was then transferred to another hospital for radiotherapy and died after transfer. Two patients had acute myocardial infarction recorded as the cause of death although no necropsy was carried out.

One patient developed a chest infection within 48 hours that was treated with appropriate antibiotics; one had a 5\% ipsilateral pneumothorax, and another had a hydropneumothorax, both of which were treated conservatively with recovery.
FOLLOW UP AND SURVIVAL

The median length of hospital stay was five days (range 1-24 days), although in several patients the stay was prolonged so that they could receive further treatment or because of unfavourable social circumstances. Sixteen patients went on to receive radiotherapy and seven chemotherapy. Of the 56 patients stented, five are alive after a mean of 207 days (range 135-274) and 51 have died with a mean survival of 77 days (range 1-477).

\section{Discussion}

There are now a number of treatment options available for the relief of distressing breathlessness due to major airway compression from inoperable carcinomas. These include endoscopic surgery, ${ }^{6}$ cryotherapy, ${ }^{7}$ laser photoresection, ${ }^{8}$ and the insertion of silastic ${ }^{9}$ or selfexpanding metal stents. ${ }^{12}$ All are usually undertaken via a rigid bronchoscope using general anaesthesia, thereby limiting their application to centres where these facilities are available.

The results presented here demonstrate that self-expanding metal stents can be inserted under local anaesthesia using the direct vision afforded by a fibreoptic bronchoscope. In our view this could be carried out in any centre where fibreoptic bronchoscopy is available. However, facilities to transfer a patient to a centre offering rigid bronchoscopy should be available in case patients cannot tolerate a fibreoptic bronchoscopy. Rigid bronchoscopy is also indicated for the removal of stents that have been positioned incorrectly. As reported previously, ${ }^{10}$ these stents can be removed up to two weeks after their insertion using rigid bronchoscopy forceps. Thereafter, the stent is covered with tracheobronchial mucosa and, indeed, may not be visible endoscopically after a few months.

In our series stenting was carried out either as a primary palliative procedure or secondary after other therapies. Equally it could be used 
as stand alone therapy or combined with a series of other palliative treatments. For patients treated before external or endobronchial radiotherapy, stenting provides protection of the airway and thereby may reduce the risk of sudden death due to complete airway obstruction as a result of post-irradiation oedema. ${ }^{11}$ This technique has two other potential advantages when compared with other palliative endoscopic procedures for inoperable tracheobronchial cancer. The first is that the insertion of the stent often results in an immediate improvement in the patient's breathlessness and/or stridor. This improvement occurs in cases with either intraluminal or extraluminal compression, or both, in contrast to laser photoresection or cryotherapy which is only of value with intraluminal tumours. Secondly, the radio-opaque metal stents can act as markers for planning of such radiotherapy.

In the previous case report on the use of selfexpanding metal stents inserted in a patient with a fibreoptic bronchoscope ${ }^{12}$ no details of objective measurements of improvement were given. In the 33 patients reported here in whom measurements were made both before and after stenting, significant improvement was seen in mean FVC, $\mathrm{FEV}_{1}, \mathrm{PEFR}$, and $\mathrm{PaO}_{2}$ following stent insertion. The use of the Karnofsky and MRC scores for performance status and degree of breathlessness in 11 patients also demonstrated a response which parallelled the subjective clinical impression shown by the improved visual analogue scores after stenting.
We thank all of the consultant colleagues in the Mersey region and North Wales who have referred patients to The Cardioand North Wales who have referred patients to The Cardiothoracic Centre, Liverpool for stenting - namely, CC Evans
and A Morris (Royal Liverpool University Hospital); T Baker (Wrexham Maelor Hospital); G Benfield (Ysbwyty Gwyenedd, Bangor); P Calverley, J Earis, P Davies, M Pearson, D CaveBigley and J Mercer (Aintree Hospital); I Casson, P Choudhury, A Ellis and B Walker (Broadgreen Hospital); B Cottier and Littler (Clatterbridge Centre for Oncology); R Donnelly, J Drakeley and A Soorae (The Cardiothoracic Centre, Liverpool); D Graham (Whiston Hospital); I Keeping (Countess of Chester Hospital); D Lawrence (Wirral Hospital); B Linaker (WarHospital); D Lawrence (Wirral Hospital); B Linaker (War-
rington Hospital); M Serlin (Southport Hospital), and J Williams (Halton Hospital).

1 Simmonds AK, Irving JD, Clarke SW, Dick R. Use of expandable metal stents in the treatment of bronchial obstruction. Thorax 1989;44:680-1.

2 George PJM, Irving JD, Mantell BS, Rudd RM. Covered expandable metal stent for recurrent tracheal obstruction. Lancet 1990;335:582-4.

3 Medical Research Council. Questionnaire on respiratory symptoms. Medical Research Council, 1966.

4 Karnofsky DA, Burchenal JH. The clinical evaluation of chemotherapeutic agents in cancer. In: Evaluation of chemotherapeutic agents. New York: Columbia University Press, 1948.

5 Aitkin RCB. Measurement of feelings using visual analogue scales. Proc $R$ Soc Med 1969;62:989-93.

6 Grillo HC. Management of tracheal tumours. Am f Surg 1982;143:697-700.

7 Maiwand MO. Cryotherapy for advanced carcinoma of the trachea and bronchi. $B M \mathcal{F}$ 1986;293:181-2.

8 Dumon JF, Reboud E, Garbe L, Aucomte F, Meric B. Treatment of tracheobronchial lesions by laser photoresection. Chest 1982;81:278-84.

9 Westaby J, Jackson JW, Pearson FG. A bifuricated silicone rubber stent for relief of tracheobronchial obstruction. $\mathcal{f}$ Thorac Cardiovasc Surg 1982;83:414-7.

10 Donnelly RJ, Hind CRK. Expandable metal stents for tracheal obstruction: permanent or temporary? A cautionary tale. Thorax 1992;47:757-8.

11 Hetzel MR. Treatment of tracheal tumours. In: Brewis RAL, Gibson GJ, Geddes DM, eds. Respiratory Medicine. LAL, Gibson GJ, Geddes DM, Bailliere Tindall, 1990:828.

12 Coolen D, Slabbynck H, Galdermans D, Van Schaardenburg C, Mortelmans LL. Insertion of a self-expandable endotracheal metal stent using topical anaesthesia and a fibreoptic bronchoscope: a comfortable way to offer palliation. Thorax 1994;49:87-8. 